\title{
The prognostic significance of estrogen receptor $\beta$ in head and neck squamous cell carcinoma
}

\author{
KRESIMIR GRSIC ${ }^{1}$, IVA LEDINSKY OPACIC ${ }^{1}$, SANDA SITIC ${ }^{2}$, \\ MARIJA MILKOVIC PERISA ${ }^{2}$, PETAR SUTON ${ }^{3}$ and BOZENA SARCEVIC ${ }^{2}$ \\ ${ }^{1}$ Division of Head and Neck Surgery, Department of Surgical Oncology; ${ }^{2}$ Department of Clinical Pathology; \\ ${ }^{3}$ Division of Radiation Oncology, Department of Radiotherapy and Medical Oncology, \\ University Hospital for Tumors, Clinical Hospital Center Sisters of Charity, 10000 Zagreb, Croatia
}

Received February 24, 2016; Accepted August 4, 2016

DOI: $10.3892 / 01.2016 .5142$

\begin{abstract}
Head and neck squamous cell carcinoma (HNSCC) is the fifth most common cancer in the world. Although multimodal and targeted therapy is now used in therapeutic procedures, the survival of patients with HNSCC has remained unchanged over the last 30 years. A number of studies have demonstrated that the increased expression of intranuclear ER $\beta$ in breast, lung and colon cancer is a favorable prognostic marker associated with higher survival rates. However, the clinical significance of sex hormone receptors in HNSCC remains unclear. The current study aimed to assess the expression of ER $\beta$ in HNSCC immunohistochemically and investigate any possible association between ER $\beta$ expression, and clinical and histopathological factors, disease recurrence and patient survival. The present study included 174 patients (165 males and 9 females) with a median age of 60.8 years (range, 39-79) with HNSCC who were primary surgically treated between January 2000 and December 2006. Immunohistochemical reactions for ER $\beta$ demonstrated that 73 patients (42\%) exhibited positive ER $\beta$ expression. Distribution of ER $\beta$ status among different head and neck subsites indicated that $>40 \%$ of all negative cases were located in laryngeal primaries, while incidence of other sublocalization within positive cases was similar and comparable $(\mathrm{P}=0.04)$. Furthermore, a correlation was observed between $\operatorname{ER} \beta$ immunopositivity and the survival of patients, with respect to the primary tumor site. Patients with ER $\beta$ positive oropharyngeal cancer had a survival rate of $35.3 \%$ at 5-years compared with $25 \%$ for patients with negative expression. However, ER $\beta$ status was not significantly correlated with any other clinical or
\end{abstract}

Correspondence to: Dr Kresimir Grsic, Division of Head and Neck Surgery, Department of Surgical Oncology, University Hospital for Tumors, Clinical Hospital Center Sisters of Charity, Ilica 197, 10000 Zagreb, Croatia

E-mail: kresimir.grsic@yahoo.com

Key words: head and neck squamous cell carcinoma, estrogen receptor $\beta$, recurrence, survival, prognosis histopathological parameter. After an average follow-up time of 38.5 months (range, 3-60 months), 54 patients (31.1\%) had succumbed to disease recurrence while 50 (28.7\%) succumbed to other causes. In conclusion, ER $\beta$ positivity indicates improved survival of patients with oropharyngeal cancer. Further research is required in order to implement novel therapeutic strategies.

\section{Introduction}

Head and neck squamous cell carcinoma (HNSCC) is the fifth most common cancer worldwide (1). Despite diagnostic advances and improvements in treatment modalities, the 5-year survival rate of such patients remains poor (2). HNSCC represents a wide spectrum of neoplasms with different patterns of biological behaviour (3) therefore, the current tumor classification is limited in its prediction of prognosis. Consumption of alcohol or tobacco is the primary risk factor for cancer of the oral cavity, larynx, oropharynx and hypopharynx, and accounts for $75 \%$ of HNSCCs (4). HNSCC usually presents with symptoms from the primary site; sore throat, hoarseness, difficulty in breathing and swallowing or ear pain (5). Enlargement of a cervical lymph node as the first presenting feature is not uncommon, particularly within certain 'silent' sites, including the tongue base, supraglottis and nasopharynx (5). Systemic metastases are uncommon at first presentation of HNSCC (6). The type of treatment required depends on the location of the primary tumor, the stage of the disease and the expected oncological/functional outcomes (4).

Early stage HNSCC (stage I/II) is usually treated with single-modality therapy (surgery or radiotherapy) while the management of locally advanced disease (stage III/IV) generally requires various combinations of treatment modalities (surgery, radiotherapy, chemotherapy or cetuximab). The 5-year survival rate for all patients with HNSCC is 40-60\% (7).

Nuclear receptors are transcription factors that modulate cell proliferation, apoptosis and migration (8). Recent data suggests that there is an association between the intranuclear overexpression of estrogen receptor (ER) $\beta$ and higher survival rates in patients with lung $(9,10)$, prostate $(11)$, breast (12) and colon cancer (13). A number of studies have demonstrated that nuclear receptors are expressed in head and neck cancer (14-20). 
Table I. Clinical and histopathological characteristics of the cohort.

\begin{tabular}{lll}
\hline Characteristic & No. patients & $\%$ \\
\hline
\end{tabular}

Age, years
Median
Range
Gender
Female

Male 165

Tumor site

\begin{tabular}{|c|c|c|}
\hline Oral cavity & 37 & 21.3 \\
\hline Oropharynx & 33 & 18.9 \\
\hline Larynx & 63 & 36.2 \\
\hline Hypopharynx & 41 & 23.6 \\
\hline \multicolumn{3}{|l|}{ pT stage } \\
\hline $\mathrm{T} 1$ & 33 & 19 \\
\hline $\mathrm{T} 2$ & 80 & 46 \\
\hline $\mathrm{T} 3$ & 41 & 23.5 \\
\hline $\mathrm{T} 4$ & 20 & 11.5 \\
\hline \multicolumn{3}{|l|}{$\mathrm{pN}$ stage } \\
\hline No & 80 & 46 \\
\hline N1 & 22 & 12.3 \\
\hline N2 & 64 & 36.8 \\
\hline N3 & 8 & 4.6 \\
\hline \multicolumn{3}{|l|}{ Differentiation } \\
\hline Well & 19 & 10.9 \\
\hline Moderate & 112 & 64.4 \\
\hline Poor & 43 & 24.7 \\
\hline \multicolumn{3}{|c|}{ Adjuvant radiotherapy } \\
\hline No & 43 & 24.7 \\
\hline Yes & 131 & 75.3 \\
\hline \multicolumn{3}{|l|}{ Survival } \\
\hline AwD & 70 & 40.2 \\
\hline StD & 54 & 31.1 \\
\hline $\mathrm{StC}$ & 50 & \\
\hline
\end{tabular}

pT stage, pathological tumor stage; pN stage, pathological regional lymph nodes stage; AwD, alive without disease; StD, succumbed to disease; StC, succumbed to other causes.

However, the clinical significance of sex hormone receptor expression in HNSCC remains unclear. The aim of the present study was to assess ER $\beta$ expression in HNSCC and investigate its association with clinical and histopathological factors, disease recurrence and patient survival. To the best of our knowledge this is the largest study examining the role of ER $\beta$ in HNSCC.

\section{Patients and methods}

Patients. A total of 174 patients with squamous cell carcinoma of oral cavity, larynx and hypopharynx were included in the
Table II. Comparison of the clinicopathological features with respect to $\operatorname{ER} \beta$ status.

\begin{tabular}{|c|c|c|c|}
\hline $\begin{array}{l}\text { Clinical } \\
\text { parameter }\end{array}$ & $\begin{array}{c}\text { ER } \beta+ \\
\text { No. patients }(\%)\end{array}$ & $\begin{array}{c}\text { ER } \beta- \\
\text { No. patients }(\%)\end{array}$ & P-value \\
\hline \multicolumn{4}{|l|}{ Age, years } \\
\hline$\leq 61$ & $38(52.1)$ & $53(52.5)$ & 0.956 \\
\hline$>61$ & 35 (47.9) & $48(47.5)$ & \\
\hline \multicolumn{4}{|l|}{ Gender } \\
\hline Male & $69(94.5)$ & $96(95.0)$ & 0.876 \\
\hline Female & $4(5.5)$ & $5(5.0)$ & \\
\hline \multicolumn{4}{|l|}{ Tumor site } \\
\hline Oral cavity & $21(28.8)$ & $16(15.8)$ & $0.040^{\mathrm{a}}$ \\
\hline Oropharynx & $17(23.3)$ & $16(15.8)$ & \\
\hline Larynx & $19(26.0)$ & $44(43.6)$ & \\
\hline Hypopharynx & $16(21.9)$ & $25(24.8)$ & \\
\hline \multicolumn{4}{|l|}{ pT stage } \\
\hline $\mathrm{T} 1 / \mathrm{T} 2$ & $40(54.8)$ & $73(72.3)$ & 0.448 \\
\hline T3/T4 & $33(45.2)$ & $28(27.7)$ & \\
\hline \multicolumn{4}{|l|}{ pN stage } \\
\hline No & $31(42.5)$ & $49(48.5)$ & 0.429 \\
\hline $\mathrm{N}+$ & $42(57.5)$ & $52(51.5)$ & \\
\hline \multicolumn{4}{|l|}{ pTNM stage } \\
\hline Stage I/II & $21(28.8)$ & $34(33.7)$ & 0.493 \\
\hline Stage III/IV & $52(71.2)$ & $67(66.3)$ & \\
\hline \multicolumn{4}{|l|}{ Differentiation } \\
\hline Well & $7(9.6)$ & $12(11.9)$ & 0.261 \\
\hline Moderate & $52(71.2)$ & $60(59.4)$ & \\
\hline Poor & $14(19.2)$ & $29(28.7)$ & \\
\hline
\end{tabular}

${ }^{\mathrm{a}} \mathrm{P}<0.05$, indicates a statistically significant result. $\mathrm{P}$-values measured by the $\chi^{2}$ test. pT stage, pathological tumor stage; $\mathrm{pN}$ stage, pathological regional lymph nodes stage; pTNM stage, pathological tumor-node-metastasis stage.

present study. The patients all underwent primary surgical treatment between January 2000 and December 2006 at the Division of Head and Neck Surgery, Department of Surgical Oncology, University Hospital for Tumors (Zagreb, Croatia). The inclusion criteria for the current retrospective study were as follows: No prior treatment for head and neck cancer and a patient follow-up period of $\geq 5$ years. Cases were classified based on the international tumor-node-metastasis (TNM) classification from 2002 (21). Patients with adverse histopathological features (extracapsular spread, multiple positive lymph nodes, stage pT3 or pT4) underwent postoperative (adjuvant) irradiation. Informed consent was obtained from each patient and the study was carried out with the approval of the Ethical Committee of the Clinical Hospital Center Sisters of Charity.

Immunohistochemistry. Formalin-fixed, paraffin-embedded tissue samples from 174 primary head and neck squamous cell carcinomas were obtained from the Department of Pathology. Representative $3 \mu \mathrm{m}$ sections of tumour tissue were cut, dewaxed 
A

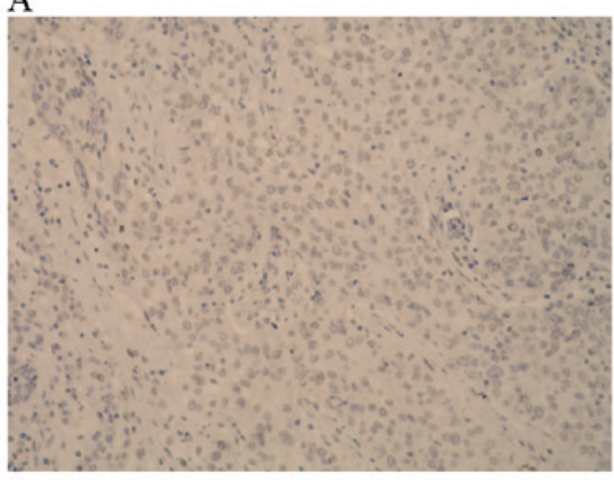

B

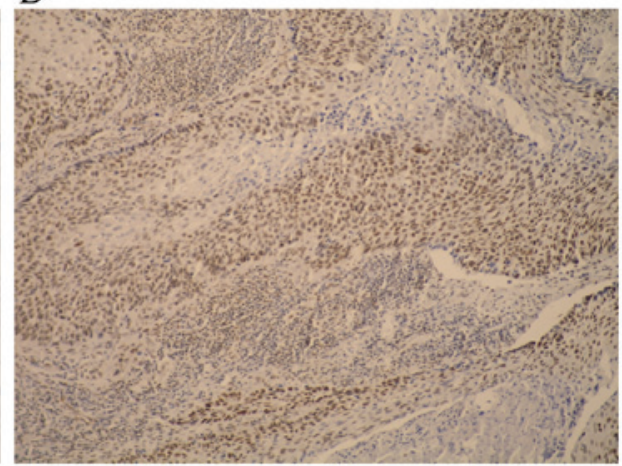

Figure 1. Immunohistochemical staining (hemotoxylin). (A) Negative reaction to ER $\beta$ in the nuclei of tumor cells (magnification, $\mathrm{x} 100$ ) (B) Strong positive reactions in the nuclei of tumor cells (magnification, $\mathrm{x} 100$ ).

in xylene and rehydrated in graded ethanol and destilled water. Antigen retrieval was performed in Tris/Ethylenediaminetetraacetic acid (EDTA), pH 9.0 buffer (Dako Target retrieval solution; catalogue number S2367; Dako, Glostrup, Denmark) for $1 \mathrm{~h}$ at $98^{\circ} \mathrm{C}$ in a water bath. Endogenous peroxidase activity was blocked with $3 \%$ hydrogen peroxide for $5 \mathrm{~min}$. Sections were washed with the buffer and subsequently incubated with mouse monoclonal anti-ER $\beta$ antibody (Product code: NCL-ER- $\beta$ Clone EMR02, dilution, 1:40, Novocastra, Laboratories, Ltd., Newcastle upon Tyne, UK) for $45 \mathrm{~min}$ at room temperature. Bound primary antibody was detected using biotinylated anti-mouse secondary antibody (EnVision FLEX, High pH Kit, catalogue number 8010; Dako, ready for use) for $45 \mathrm{~min}$ and visualized with diaminobenzidine as chromogen on Autostainer Link 48 (Dako). Slides were counterstained with hematoxilyn, dehydrated, cleared and cover-slipped. A breast cancer tissue sample was used as a positive control.

Stained tissue sections were evaluated by an experienced pathologist. Nuclear staining was considered positive and $>100$ cells were counted. Separate scores were assigned to each sample according to the percentage of positive nuclei observed (0-100\%). The following scoring system was used: 0 , no staining of tumour cells (Fig. 1A); 1, positive staining $<10 \%$ of tumour cells; 2 , positive staining in $11-50 \%$ of tumour cells; 3 , positive staining in $>51 \%$ tumour cells (Fig. 1B). For the purpose of statistical analysis, cases with scores of 0 and 1 were considered negative and cases with scores of 2 or 3 were considered positive (14).

Statistical analysis. Normality of data distribution was assessed with Smirnov-Kolmogorov test and due to the results obtained, appropriate non-parametric tests were used in analyses. Differences between ER groups were analyzed with the $\chi^{2}$ test (categorical values) and Mann-Whitney U test (quantitative values). Spearman correlation coefficients were used to analyze associations between total survival time and other clinical variables for each tumor location. Overall survival (OS) was calculated using the Kaplan-Meier method, while the log-rank test tested the differences between the actuarial curves. OS was calculated from the time of surgery to death resulting from all causes. IBM SPSS Statistics ver. 21 (Armonk, NY, USA) was used in all statistical tests. $\mathrm{P}<0.05$ was considered to indicate a statistically significant difference.

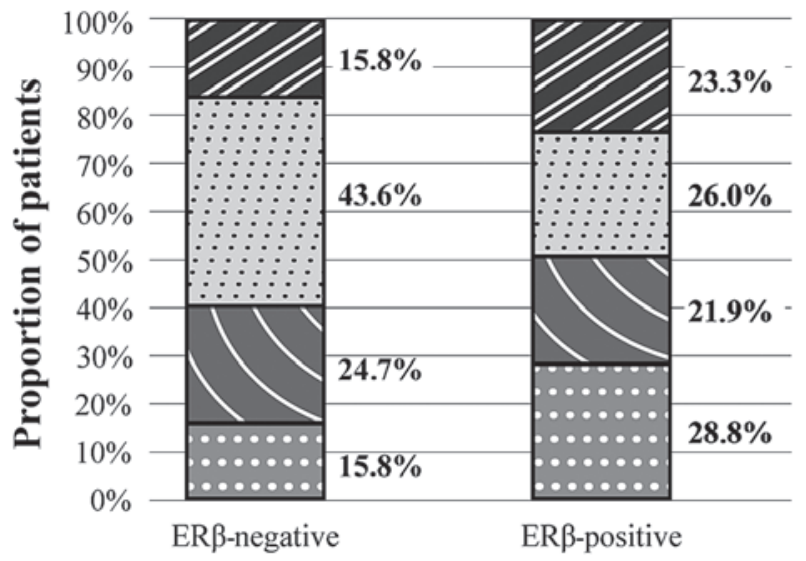

\section{Tumor subsite}

- oral cavity $\mathbf{\nabla}$ hypopharynx $\quad$ larynx $\quad$ oropharynx

Figure 2. Distribution of ER $\beta$ status among head and neck subsites.

\section{Results}

The present study included 165 male and 9 female patients with a median age of 60.8 years, (range, 39-79), of which 80 (46\%) exhibited no evidence of cervical lymph node metastasis, while 94 (54\%) had neck metastases. The clinicopathological characteristics of the study group are listed in Table I.

Immunohistochemistry for ER $\beta$ indicated positive staining in 73 patients (42\%). Distribution of ER $\beta$ status among different head and neck subsites is listed in Fig. 2. A higher proportion of the ER $\beta$ negative cases $(>40 \%)$ were located in laryngeal primaries compared with other areas, whereas incidence of other sublocalization within ER $\beta$ positive cases were similar (Fig. 2). This association was statistically significant $(\mathrm{P}=0.04$; Table II).

The univariate correlations between clinicopathological features and ER $\beta$ status are presented in Table II. Positive $\operatorname{ER} \beta$ status was not significantly correlated with any clinicopathohistological parameter other than the survival of patients with respect to the primary tumor site.

Patients with oropharyngeal cancer with specimens that demonstrated an ER $\beta$ positive intranuclear reaction had an OS rate of $35.3 \%$ at 5 years compared with $25 \%$ for patients with negative reaction, a statistically significant difference (log-rank 
A

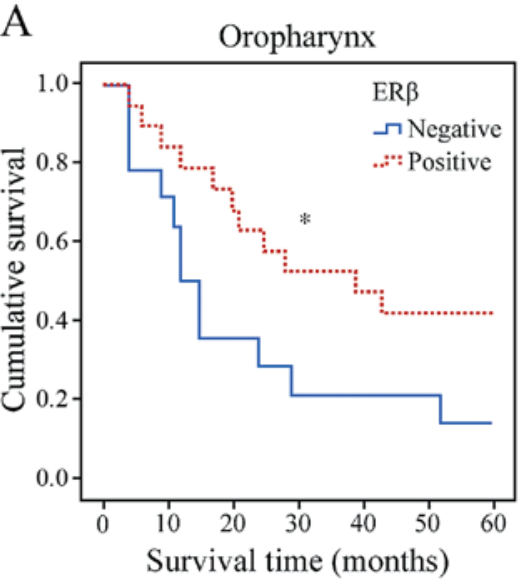

C

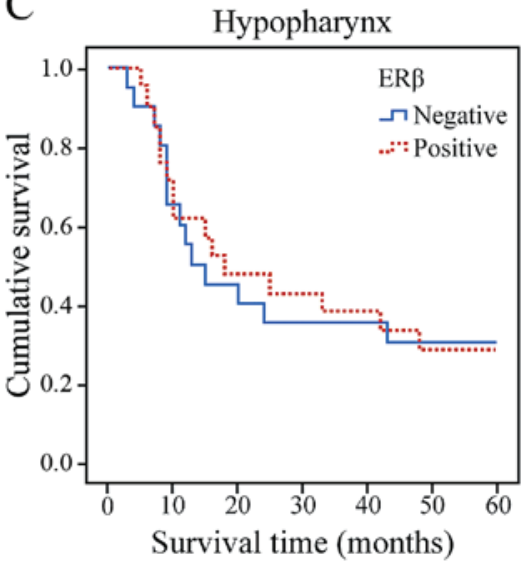

B

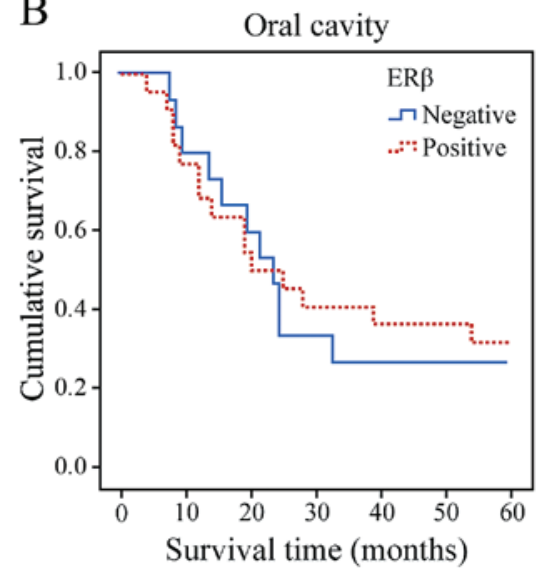

D

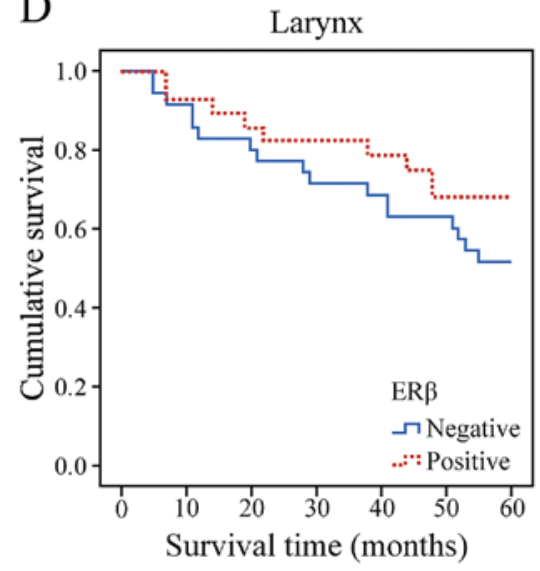

Figure 3. Kaplan-Meier survival estimates. Association between level of ER $\beta$ expression and primary tumor subsites with respect to survival in the (A) oropharynx, (B) oral cavity (C) hypopharynx and (D) larynx. ${ }^{*} \mathrm{P}<0.05$.

test, $\mathrm{P}=0.045)$ (Fig. 3A). By contrast, there was no significant association between ER $\beta$ expression and other primary tumor subsites with respect to survival (Fig. 3B-D). By the end of the study, 54 (31.1\%) patients had died of disease recurrence while $50(28.7 \%)$ had died of other causes. Follow-up information was available for all patients and average follow-up time was 38.5 months (range, 3-60 months).

\section{Discussion}

A previous report has suggested that ER-mediated signals and pathways serve a critical role in malignant tumor growth, progression and metastasis (8). The most comprehensive analysis was performed on patients with breast cancer where positive expression of ER $\beta$ was associated with increased response rates to ER antagonist therapy with tamoxifen $(12,22)$. However, the role of ER signaling in other malignancies remains unclear. Similarily, the significance of ER expression in HNSCC and its biological role in cell invasion, proliferation, metastasis and survival is controversial.

In the head and neck region, ER expression was initially evaluated in laryngeal cancer. This type of cancer is 11 times more common in males than females, despite similar rates of alcohol abuse and smoking in both genders $(15,23)$. Previous studies have demonstrated that $23-79 \%$ of laryngeal cancer cases express ERs $(16-18,24)$, concluding that positive ER expression is gender independent with a positive prognostic influence on survival. However, other authors have not been able to identify ER expression in laryngeal cancer $(25,26)$, therefore laryngeal carcinogenesis may be a hormonally independant process. Non-identification of ER in epithelial components of the normal larynges and laryngeal carcinomas has been confirmed (27).

A previous study examined the role of ER $\beta$ in laryngeal cancer and demonstrated that its expression was positively correlated with the maintenance of E-cadherin and $\beta$-catenin at cell junctions and negatively with increased TNM stage (19). This suggests that ER $\beta$ serves a protective role in the pathogenesis of this malignancy.

A study by Nozoe et al (28) demonstrated that positive expression of $\mathrm{ER} \alpha$ in combination with negative expression of ER $\beta$ proved to be an unfavorable prognostic indicator with respect to the survival of patients with esophageal squamous cell carcinoma (SCC). Wang et al (29) have reported a correlation between positive ER $\beta$ expression and lower malignant potential in oesophageal SCC. However, Dong et al (30) reported that $\mathrm{ER} \alpha$ and ER $\beta$ levels were inversely correlated and that downregulation of $E R \alpha$ and upregulation of $E R \beta$ expression may indicate poor prognosis in patients with oesophageal SCC.

Few studies have investigated the role of ER expression in HNSCC. Lukits et al (14) performed a study on 67 patients with carcinoma of the larynx, oral cavity and hypopharynx. ER $\alpha$ and ER $\beta$ expressions were identified in $50 \%$ of patients and had no significant influence on patient prognosis. 
Egloff et al (20) demonstrated that treating HNSCC cells with estrogen and epidermal growth factor (EGF) significantly increased cell invasion compared to treatment alone, whereas inhibiting the two pathways reduced cell invasion. Futhermore, patients with high intranuclear ER $\alpha$ and tumor EGFR levels exhibited significantly reduced rates of progression-free survival; ER $\beta$ expression, however, did not significantly affect patient survival (20).

Ishida et al (31) examined 4 cell lines and 15 tumors from patients with oral SCC. High ER $\beta$ expression was observed in the tumor cells of human primary SCC tissues and various SCC cultured cell lines. Treatment with the ER antagonists tamoxifen and raloksifen resulted in SCC apoptotic cell death and $\operatorname{Er} \beta$ knockdown by small interfering RNA inhibited SCC proliferation (31).

In the current study, $73(42 \%)$ patients exhibited intranuclear ER $\beta$ expression, which is in accordance with prior reports (14). Distribution of ER $\beta$ status among different head and neck subsites demonstrated that almost half of ER $\beta$ negative cases were located in the larynx, while incidence of all tumor sublocalizations within ER $\beta$ positive cases was similar and comparable. Further studies are required to evaluate the effects of this aberrant distribution.

According to the results of the present study, positive expression of ER $\beta$ indicates improved survival in patients with oropharyngeal cancer. To the best of our knowledge, this is the first study suggesting that positive expression of ER $\beta$ may be an indicator of improved survival of patients with oropharyngeal primaries. However, this is only the case in patients with oropharyngeal cancer-in other subsites, there was no correlation between ER $\beta$ expression and prolonged survival.

In conclusion, given the positive results of antihormonal therapy administration in patients with breast cancer and similar effects observed in HNSCC cell lines, future studies are necessary in order to implement novel therapeutic strategies.

\section{References}

1. Parkin DM, Bray F, Ferlay J and Pisani P: Global cancer statistics, 2002. CA Cancer J Clin 55: 74-108, 2005.

2. Takenaka Y, Yasui T, Enomoto K, Miyabe H, Morizane N, Ashida N, Shimizu K, Hirose M, Yamamoto Y and Uno A: Health insurance status and survival among patients with head and neck cancer in Japan. Int J Clin Oncol 21: 517-522, 2016.

3. Razzouk S: Translational genomics and head and neck cancer: Toward precision medicine. Clin Genet 86: 412-421, 2014

4. Machiels JP, Lambrecht M, Hanin FX, Duprez T, Gregoire V, Schmitz S and Hamoir M: Advances in the management of squamous cell carcinoma of the head and neck. F1000Prime Rep 6: 44, 2014.

5. Sanderson RJ and Ironside JA: Squamous cell carcinomas of the head and neck. BMJ 325: 822-827, 2002.

6. Merino OR, Lindberg RD and Fletcher GH: An analysis of distant metastases from squamous cell carcinoma of the upper respiratory and digestive tracts. Cancer 40: 145-151, 1977.

7. Grégoire V, Lefebvre JL, Licitra L and Felip E; EHNSESMO-ESTRO Guidelines Working Group: Squamous cell carcinoma of the head and neck: EHNS-ESMO-ESTRO clinical practice guidelines for diagnosis, treatment and follow-up. Ann Oncol 21 (Suppl 5): v184-v186, 2010.

8. Schweitzer A, Knauer SK and Stauber RH: Nuclear receptors in head and neck cancer: Current knowledge and perspectives. Int J Cancer 126: 801-809, 2010.

9. Wu CT, Chang YL, Shih JY and Lee YC: The significance of estrogen receptor beta in 301 surgically treated non-small cell lung cancers. J Thorac Cardiovasc Surg 130: 979-986, 2005.
10. Kawai H, Ishii A, Washiya K, Konno T, Kon H, Yamaya C, Ono I, Minamiya Y and Ogawa J: Estrogen receptor alpha and beta are prognostic factors in non-small cell lung cancer. Clin Cancer Res 11: 5084-5089, 2005.

11. Cheng J, Lee EJ, Madison LD and Lazennec G: Expression of estrogen receptor beta in prostate carcinoma cells inhibits invasion and proliferation and triggers apoptosis. FEBS Lett 566: 169-172, 2004.

12. Reese JM, Suman VJ, Subramaniam M, Wu X, Negron V, Gingery A, Pitel KS, Shah SS, Cunliffe HE, McCullough AE, et al: ER $\beta 1$ : Characterization, prognosis, and evaluation of treatment strategies in ER $\alpha$-positive and -negative breast cancer. BMC Cancer 14: 749, 2014.

13. Jassam N, Bell SM, Speirs V and Quirke P: Loss of expression of oestrogen receptor beta in colon cancer and its association with Dukes' staging. Oncol Rep 14: 17-21, 2005.

14. Lukits J, Remenár E, Rásó E, Ladányi A, Kásler M and Tímár J: Molecular identification, expression and prognostic role of estrogen-and progesterone receptors in head and neck cancer. Int J Oncol 30: 155-60, 2007.

15. Ferlay J, Autier P, Boniol M, Heanue M, Colombet M and Boyle P: Estimates of the cancer incidence and mortality in Europe in 2006. Ann Oncol 18: 581-592, 2007.

16. Budai B, Remenár E, Orosz Z, Számel I, Kralovánszky J and Kásler M: Steroid hormone receptors in squamous cell carcinoma of the head and neck. Orv Hetil 138: 723-727, 1997 (In Hungarian).

17. Virolainen E, Tuohimaa P, Aitasalo K, Kyttä J and VanharantaHiltunen R: Steroid hormone receptors in laryngeal carcinoma. Otolaryngol Head Neck Surg 94: 512-517, 1986.

18. Oğretmenoğlu $\mathrm{O}$ and Ayas K: Laryngeal carcinoma and estrogen receptor analysis in patients after long-term follow-up. Eur Arch Otorhinolaryngol 255: 457-461, 1998.

19. Goulioumis AK, Fuxe J, Varakis J, Repanti M, Goumas P and Papadaki H: Estrogen receptor-beta expression in human laryngeal carcinoma: Correlation with the expression of epithelial-mesenchymal transition specific biomarkers. Oncol Rep 22: 1063-1068, 2009.

20. Egloff AM, Rothstein ME, Seethala R, Siegfried JM, Grandis JR and Stabile LP: Cross-talk between estrogen receptor and epidermal growth factor receptor in head and neck squamous cell carcinoma. Clin Cancer Res 15: 6529-6540, 2009.

21. Edge S, Byrd DR, Compton CC, Fritz AG, Greene FL and Trotti A (eds): AJCC Cancer Staging Manual. 7th edition, Springer, New York, pp29-35, 2010.

22. Niu XL, Wang Y, Yao Z, Duan H, Li Z, Liu W, Zhang H and Deng WM: Autocrine interferon- $\gamma$ may affect malignant behavior and sensitivity to tamoxifen of MCF-7 via estrogen receptor $\beta$ subtype. Oncol Rep 34: 3120-3130, 2015.

23. Licitra L, Bernier J, Grandi C, Locati L, Merlano M, Gatta G and Lefebvre JL: Cancer of the larynx. Crit Rev Oncol Hematol 47: 65-80, 2003.

24. Bianchini C, Pastore A, Pelucchi S, Torreggiani E, Lambertini E, Marchesi E, Magri E, Frasson C, Querzoli P and Piva R: Sex hormone receptor levels in laryngeal carcinoma: A comparison between protein and RNA evaluations. Eur Arch Otorhinolaryngol 265: 1089-1094, 2008.

25. Hagedorn HG and Nerlich AG: Analysis of sex-hormone-receptor expression in laryngeal carcinoma. Eur Arch Otorhinolaryngol 259: 205-210, 2002.

26. Schuller DE, Abou-Issa H and Parrish R: Estrogen and progesterone receptors in head and neck cancer. Arch Otolaryngol 110: 725-727, 1984.

27. Ferguson BJ, Hudson WR and McCarty KS Jr: Sex steroid receptor distribution in the human larynx and laryngeal carcinoma. Arch Otolaryngol Head Neck Surg 113: 1311-1315, 1987.

28. Nozoe T, Oyama T, Takenoyama M, Hanagiri T, Sugio K and Yasumoto K: Significance of immunohistochemical expression of estrogen receptors alpha and beta in squamous cell carcinoma of the esophagus. Clin Cancer Res 13: 4046-4050, 2007.

29. Wang QM, Qi YJ, Jiang Q, Ma YF and Wang LD: Relevance of serum estradiol and estrogen receptor beta expression from a high-incidence area for esophageal squamous cell carcinoma in China. Med Oncol 28: 188-193, 2011.

30. Dong J, Jiang SW, Niu Y, Chen L, Liu S, Ma T, Chen X, Xu L, Su Z and Chen H: Expression of estrogen receptor $\alpha$ and $\beta$ in esophageal squamous cell carcinoma. Oncol Rep 30: 2771-2776, 2013.

31. Ishida H, Wada K, Masuda T, Okura M, Kohama K, Sano Y, Nakajima A, Kogo M and Kamisaki Y: Critical role of estrogen receptor on anoikis and invasion of squamous cell carcinoma. Cancer Sci 98: 636-643, 2007. 